\title{
Expression of Myeloid Antigen in Neoplastic Plasma Cells Is Related to Adverse Prognosis in Patients with Multiple Myeloma
}

\author{
Hyoeun Shim, ${ }^{1}$ Joo Hee Ha, ${ }^{1}$ Hyewon Lee, ${ }^{2,3}$ Ji Yeon Sohn, ${ }^{1}$ Hyun Ju Kim, \\ Hyeon-Seok Eom, ${ }^{2}$ and Sun-Young Kong ${ }^{1,4}$ \\ ${ }^{1}$ Department of Laboratory Medicine, Center for Diagnostic Oncology, Research Institute and Hospital, National Cancer Center, \\ 323 Ilsan-ro, Ilsandong-gu, Goyang, Gyeonggi-do 410-769, Republic of Korea \\ ${ }^{2}$ Hematologic-Oncology Clinic, Center for Specific Organs Cancer, Research Institute and Hospital, National Cancer Center, \\ 323 Ilsan-ro, Ilsandong-gu, Goyang, Gyeonggi-do 410-769, Republic of Korea \\ ${ }^{3}$ Hematologic Malignancy Branch, Research Institute and Hospital, National Cancer Center, 323 Ilsan-ro, Ilsandong-gu, \\ Goyang-si, Gyeonggi-do 410-769, Republic of Korea \\ ${ }^{4}$ Translational Epidemiology Research Branch, Research Institute and Hospital, National Cancer Center, 323 Ilsan-ro, \\ Ilsandong-gu, Goyang-si, Gyeonggi-do 410-769, Republic of Korea
}

Correspondence should be addressed to Hyeon-Seok Eom; hseom@ncc.re.kr and Sun-Young Kong; ksy@ncc.re.kr

Received 21 February 2014; Revised 28 April 2014; Accepted 8 May 2014; Published 4 June 2014

Academic Editor: Dong Soon Lee

Copyright (C) 2014 Hyoeun Shim et al. This is an open access article distributed under the Creative Commons Attribution License, which permits unrestricted use, distribution, and reproduction in any medium, provided the original work is properly cited.

\begin{abstract}
We evaluated the association between the expression of myeloid antigens on neoplastic plasma cells and patient prognosis. The expression status of CD13, CD19, CD20, CD33, CD38, CD56, and CD117 was analyzed on myeloma cells from 55 newly diagnosed patients, including $36 \mathrm{men}$ (65\%), of median age 61 years (range: 38-78). Analyzed clinical characteristics and laboratory parameters were as follows: serum $\beta 2$-microglobulin, lactate dehydrogenase, calcium, albumin, hemoglobin, serum creatinine concentrations, bone marrow histology, and cytogenetic findings. CD13+ and CD33+ were detected in 53\% and 18\%, respectively. Serum calcium $(P=0.049)$ and LDH $(P=0.018)$ concentrations were significantly higher and morphologic subtype of immature or plasmablastic was more frequent in CD33+ than in CD33- patients $(P=0.022)$. CD33 and CD13 expression demonstrate a potential prognostic impact and were associated with lower overall survival (OS; $P=0.001$ and $P=0.025$ ) in Kaplan-Meier analysis. Multivariate analysis showed that CD33 was independently prognostic of shorter progression free survival $(\mathrm{PFS} ; P=0.037)$ and OS $(P=0.001)$ with correction of clinical prognostic factors. This study showed that CD13 and CD33 expression associated with poor prognosis in patients with MM implicating the need of analysis of these markers in MM diagnosis.
\end{abstract}

\section{Introduction}

Flow cytometry (FCM) is widely used for the diagnosis and monitoring of hematological disorders, such as acute leukemias or lymphomas, in order to detect and characterize abnormal compartments or to enumerate rare events [1]. Flow cytometric analysis of neoplastic plasma cells in patients diagnosed with multiple myeloma (MM) can distinguish clonal cell populations and can be used to determine the numbers of neoplastic cells and to monitor residual disease during treatment [2].
In plasma cells, aberrant expression of CD56 and CD28 but lack of CD19 and CD27 showed the association with malignancy [3]. Downregulation of CD56 and a higher expression of CD44 have been associated with extramedullary spreading of malignant plasma cells $[4,5]$ and expression of CD28 has been related to disease activity $[6,7]$. Though many studies have reported the associations between the expression of several antigens, including CD19, CD28, CD56, and CD117, and patient prognosis [8-10], no consensus has been reached regarding the expression status of antigens and their clinical relevance. Here we evaluated the impact of 
antigen expression of neoplastic plasma cells on survival of patients diagnosed with MM.

\section{Materials and Methods}

Bone marrow (BM) aspiration samples were obtained from 55 patients newly diagnosed with MM from November 2007 to March 2013. Flow cytometric analyses perfomed in condition of plasma cells over $5 \%$ in the specimens. Whole erythrocytelysed BM samples were stained using the following fourcolor combinations of antibodies (FITC/PE/PerCP/APC): CD19/CD117/CD138/CD45, CD20/CD33/CD138/CD45, CD38/CD13/CD138/CD45, -/CD56/CD138/CD45, and cytoKappa/cyto-Lambda/CD138/CD45. Antibody combinations were changed once from anti-CD38/CD13/CD138/CD45 to anti-CD38/CD28/CD138/CD45 during the study period. To assess antigens expression an aliquot of approximately $1 \times 10^{6}$ cells was labeled with preconjugated monoclonal antibodies in accordance with the manufacturer's recommendations (BD Biosciences, USA). The cells were then washed with phosphate buffered saline (PBS). For CD138 gating, at least $1 \times 10^{3}$ events per tube were acquired. Analyses were carried out using the FACS Diva software (BD Biosciences). Cells were also incubated with irrelevant isotype-matched antibodies to determine background fluorescence. Side scatter and high level expression of CD138 were used to gate each preparation of plasma cells. CD138 gated cells from patients with $\mathrm{MM}$ were retrospectively defined as neoplastic plasma cells when it was diagnosed as monoclonal gammopathy on serum and/or urine electrophoresis and light chain restriction on immunohistochemical staining of BM biopsy section. Positivity for antigen expression on flow cytometry was defined as staining of $>20 \%$ of the cells.

Patient characteristics were retrospectively evaluated, including laboratory parameters including serum $\beta 2$-microglobulin, calcium, albumin, hemoglobin, lactate dehydrogenase $(\mathrm{LDH})$, serum creatinine concentrations, and immunoglobulin type of monoclonal protein. Fifty-five patients with MM were analyzed, 36 males (65\%) and 19 females (35\%), of median age 61 years (range: $38-78$ years) (Table 1). BM histologic findings were classified as mature $(n=39)$, immature $(n=9)$, plasmablastic $(n=2)$, or pleomorphic $(n=5)$ myeloma cell types. Infiltration was categorized by interstitial $(n=16)$, focal $(n=3)$, or diffuse $(n=36)$ pattern. The FISH panels included $p 53$ (17p13), Rb1 (13q14), IGH/FGFR t(4;14), and trisomy lq (1q21). Cytogenetic abnormalities of $t(4 ; 14)$ or $\operatorname{del}(17 \mathrm{p})$ were designated as high risk [11].

The initial treatment regimen consisted of including thalidomide and dexamethasone (57\%), bortezomib (19\%), combination of thalidomide and bortezomib (6\%), lenalidomide (4\%), and others (14\%). Autologous peripheral blood stem cell transplantation (PBSCT) was performed in 33\% of patients. Stage was classified by the international staging system and Durie-Salmon staging system [12, 13]. Risk group and disease progression were defined according to the International Myeloma Working Group (IMWG) risk

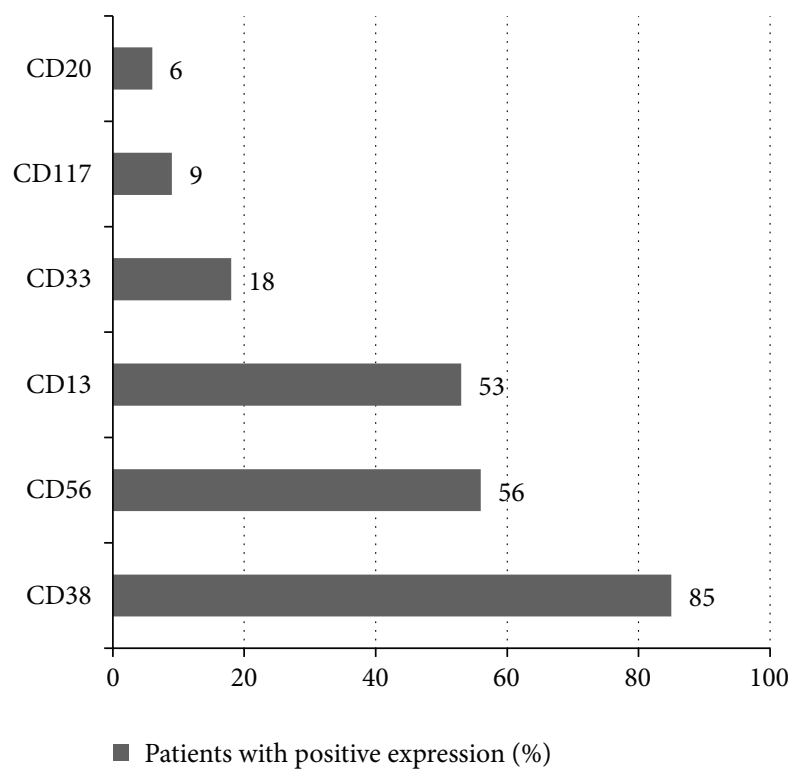

FIGURE 1: Frequency of antigen expression in patients newly diagnosed with multiple myeloma. CD56 and CD13 were the most common aberrant antigens in neoplastic plasma cells (56\% and 53\%, resp.), followed by CD33, CD117, and CD20. CD13 and CD33, the traditional myeloid markers, showed relatively high prevalence.

stratification and response criteria for MM, respectively [14, 15].

Progression-free survival (PFS) was calculated from the date of diagnosis to the date of relapse, disease progression, or death from any cause. Overall survival (OS) was calculated as the time from the date of diagnosis to death from any cause. PFS and OS were determined by the Kaplan-Meier method and log-rank test. Continuous variables were compared using independent $t$-tests or Mann-Whitney tests and categorical variables using Pearson chi-square or Fisher's exact tests. Multivariate analysis was performed using Cox regression analysis. Data were analyzed using SPSS 21 software (IBM Corp. 2012, IBM SPSS Statistics, version 21.0, Armonk, NY). This study was approved by the institutional review board of National Cancer Center of Korea (NCCNCS-13-774).

\section{Results}

The expression of CD38 was detected in $85 \%$ of cases ( 47 of 55) in CD138+ gated plasma cells. The expression of CD56, a marker involved in anchoring plasma cells to stromal structures, was found in 56\% of cases (31 of 55). CD13 and CD33, the markers of myeloid lineage, were detected in $53 \%$ (20 of 38 ) and $18 \%$ (10 of 55) of cases, respectively. CD117, a tyrosine kinase receptor was detected in $9 \%$ (5 of $54)$. CD20, an antigen associated with the early stages of Bcell maturation, was detected in only 6\% (3 of 55) of cases (Figure 1).

CD33 positivity was significantly associated with higher serum calcium $(P=0.049)$ and LDH $(P=0.018)$ concentrations (Table 2). Moreover, immature and plasmablastic cell type was more frequently observed in CD33+ than CD33- 
TABLE 1: Clinical characteristics of the 55 patients with multiple myeloma.

\begin{tabular}{|c|c|}
\hline Characteristics & Number (\%) or median (range) \\
\hline Number of patients & 55 \\
\hline Age & $61(38-78)$ \\
\hline Gender (male : female) & $36: 19(65: 35)$ \\
\hline Durie-Salmon stage (I : II : III) & $5: 10: 40(9: 18: 73)$ \\
\hline ISS stage (I : II : III) & $22: 18: 15(40: 33: 27)$ \\
\hline Calcium (mg/dL) & $9.1(7.2-13.0)$ \\
\hline Creatinine (mg/dL) & $1.2(0.7-3.9)$ \\
\hline Albumin (mg/dL) & $4.0(2.3-4.9)$ \\
\hline$\beta 2-$ Microglobulin (mg/dL) & $3.8(1.6-19.0)$ \\
\hline Hemoglobin (g/dL) & $10.3(6.0-16.2)$ \\
\hline Lactate dehydrogenase (U/L) & $167(79-1832)$ \\
\hline C-reactive protein (mg/dL) & $0.27(0-10.01)$ \\
\hline $\operatorname{IgG}: \operatorname{Ig} \mathrm{A}: \operatorname{IgM}: \operatorname{IgD}: \operatorname{IgE}:$ light $^{*}:$ biclonal & $33: 11: 0: 0: 0: 9: 2(60: 20: 0: 0: 0: 16: 4)$ \\
\hline Kappa : Lambda (electrophoresis) & $23: 22^{\dagger}(51: 49)$ \\
\hline \multicolumn{2}{|l|}{ Plasma cell type } \\
\hline Mature & $39(71)$ \\
\hline Immature & $9(16)$ \\
\hline Plasmablastic & $2(4)$ \\
\hline Pleomorphic & $5(9)$ \\
\hline \multicolumn{2}{|l|}{ Infiltration pattern } \\
\hline Interstitial & $16(29)$ \\
\hline Focal & $3(5)$ \\
\hline Diffuse & $36(66)$ \\
\hline Frequency of CD138-positive cells on biopsy ${ }^{\ddagger}$ & $80(10-100)$ \\
\hline \multicolumn{2}{|l|}{ Cytogenetics (FISH) } \\
\hline 1q gain ${ }^{\dagger}$ & $21 / 47(45)$ \\
\hline $13 q$ deletion ${ }^{\dagger}$ & $19 / 47(40)$ \\
\hline $\mathrm{t}(4 ; 14)^{\dagger}$ & $8 / 48(17)$ \\
\hline $17 \mathrm{p}$ deletion ${ }^{\dagger}$ & $2 / 41(5)$ \\
\hline
\end{tabular}

ISS: international staging system; FISH: fluorescent in situ hybridization; ${ }^{*}$ light chain type; ${ }^{\dagger}$ absent values due to tests not done; the percentages are calculated based on the number of tests completed; ${ }^{\ddagger}$ immunohistochemical stain on bone marrow biopsy.

patients $(P=0.022)$. CD13 expression did not show the association with clinical characteristics except infiltration pattern $(P=0.046)$. High risk cytogenetics, IMWG risk stratification, ISS stage, or Durie-Salmon stage has no significant difference in expression of myeloid antigens. Univariate analysis showed that $\mathrm{CD} 13$ positivity $(P=0.008), \beta 2$ microglobulin $>3.5 \mathrm{mg} / \mathrm{dL}(P=0.003)$, and LDH $>202 \mathrm{U} / \mathrm{L}$ $(P=0.007)$ were significantly associated with shorter PFS. In addition, $\mathrm{CD} 13$ positivity $(P=0.025), \mathrm{CD} 33$ positivity $(P=0.001), \beta 2$-microglobulin $>3.5 \mathrm{mg} / \mathrm{dL}(P=0.007)$, and $\mathrm{LDH}>202 \mathrm{U} / \mathrm{L}(P<0.001)$ were significantly associated with shorter OS.

The prognostic indicators found to be significant in univariate analyses were included in multivariate analyses. CD33 positivity was the factor independently prognostic for OS (HR: 14.2, 95\% CI: 3.3-61.8, $P<0.001$ ). $\beta 2$-Microglobulin $>3.5 \mathrm{mg} / \mathrm{dL}$ was another independent prognostic factor associated with PFS (HR: 6.93, 95\% CI: 2.0-24.1, $P=0.002$ ) (Table 3).
CD33 and CD13 expression were associated with lower OS $(P=0.001$ and $P=0.025)$ at a median followup of 51 months. The estimated 2 -year OS rate was significantly lower in CD33+ than in CD33- patients (38\% versus 78\%, $P=0.046)$ and $\mathrm{CD} 13+$ than in $\mathrm{CD} 13$ - patients (55\% versus $83 \%, P=0.046)$. PFS was significantly shorter in $\mathrm{CD} 13+$ than CD13- patients $(P=0.008$, Figure 2$)$. Other antigens did not influence OS or PFS as follows: CD56 $(P=0.252, P=0.417)$, CD117 $(P=0.912, P=0.975)$, and CD20 $(P=0.679$, $P=0.253)$.

The numbers of patients with $\mathrm{CD} 13+/ \mathrm{CD} 33+, \mathrm{CD} 13+/$ CD33-, CD13-/CD33+, and CD13-/CD33- groups were 3, 17, 3 , and 15 , respectively, and the $\mathrm{CD} 13+/ \mathrm{CD} 33+$ group showed significantly shorter PFS and OS than other groups (Figure 3 ).

\section{Discussion}

This study showed myeloid antigens CD13 and CD33 were associated with poor prognosis in MM patients. Univariate analysis showed that both antigens were associated with 
TABLE 2: Comparison of clinical data in groups positive and negative for CD33 and CD13.

\begin{tabular}{|c|c|c|c|c|c|c|}
\hline \multirow{2}{*}{ Clinical parameters } & \multicolumn{3}{|c|}{$\begin{array}{c}\text { CD33 } \\
\text { Mean or number (\%) }\end{array}$} & \multicolumn{3}{|c|}{$\begin{array}{c}\text { CD13 } \\
\text { Mean or number (\%) }\end{array}$} \\
\hline & $\begin{array}{l}\text { Negative } \\
(N=44)\end{array}$ & $\begin{array}{l}\text { Positive } \\
(N=10)\end{array}$ & $P$ & $\begin{array}{l}\text { Negative } \\
(N=18)\end{array}$ & $\begin{array}{l}\text { Positive } \\
(N=20)\end{array}$ & $P$ \\
\hline Age & 61.2 & 61.1 & 0.978 & 61.9 & 60.4 & 0.688 \\
\hline Calcium (mg/dL) & 9.03 & 9.78 & 0.049 & 9.03 & 9.60 & 0.145 \\
\hline Creatinine $(\mathrm{mg} / \mathrm{dL})$ & 1.36 & 1.28 & 0.710 & 1.32 & 1.50 & 0.434 \\
\hline Albumin (mg/dL) & 3.81 & 3.55 & 0.270 & 3.66 & 3.91 & 0.243 \\
\hline$\beta 2-$ Microglobulin (mg/dL) & 4.76 & 4.71 & 0.966 & 3.09 & 4.28 & 0.635 \\
\hline Hemoglobin (g/dL) & 10.6 & 9.8 & 0.277 & 10.3 & 10.6 & 0.687 \\
\hline LDH (U/L) & 172 & 369 & 0.018 & 140 & 302 & 0.078 \\
\hline Monoclonal heavy chain & & & 0.793 & & & 0.454 \\
\hline IgG & $24(77)$ & $7(23)$ & & $12(60)$ & $8(40)$ & \\
\hline $\operatorname{Ig} \mathrm{A}$ & $10(91)$ & $1(9)$ & & $2(29)$ & $5(71)$ & \\
\hline $\operatorname{IgD}$ & $3(100)$ & $0(0)$ & & $1(33)$ & $2(67)$ & \\
\hline Light chain only & $7(29)$ & $2(71)$ & & $3(38)$ & $5(52)$ & \\
\hline Monoclonal light chain & & & 0.603 & & & 0.207 \\
\hline Kappa & $27(82)$ & $6(18)$ & & $9(39)$ & $14(61)$ & \\
\hline Lambda & $17(81)$ & $4(9)$ & & $9(60)$ & $6(40)$ & \\
\hline BM aspirate plasma cell (\%) & 38 & 48 & 0.903 & 36 & 48 & 0.198 \\
\hline Plasma cell type & & & 0.022 & & & 0.519 \\
\hline Mature & $35(90)$ & $4(10)$ & & $14(54)$ & $12(46)$ & \\
\hline Immature & $4(50)$ & $4(50)$ & & $2(29)$ & $5(71)$ & \\
\hline Plasmablastic & $1(50)$ & $1(50)$ & & $0(0)$ & $1(100)$ & \\
\hline Pleomorphic & $4(80)$ & $1(20)$ & & $2(50)$ & $2(50)$ & \\
\hline Infiltration pattern & & & 0.487 & & & 0.046 \\
\hline Interstitial & $14(88)$ & $2(12)$ & & $5(100)$ & $0(0)$ & \\
\hline Focal & $2(67)$ & $1(33)$ & & $1(50)$ & $1(50)$ & \\
\hline Diffuse & $28(80)$ & $7(20)$ & & $12(44)$ & $15(56)$ & \\
\hline \multicolumn{7}{|l|}{ Cytogenetics (FISH) ${ }^{\ddagger}$} \\
\hline $\mathrm{t}(4 ; 14)$ & $7 / 40$ & $1 / 4$ & 0.566 & $3 / 18$ & $4 / 19$ & 0.532 \\
\hline 1q amplification & $14 / 39$ & $4 / 7$ & 0.258 & $6 / 18$ & $9 / 19$ & 0.297 \\
\hline 13q deletion & $14 / 39$ & $4 / 7$ & 0.258 & $5 / 18$ & $8 / 19$ & 0.286 \\
\hline $17 \mathrm{p}$ deletion & $2 / 33$ & $0 / 7$ & 0.677 & $0 / 15$ & $2 / 15$ & 0.241 \\
\hline Cytogenetic high risk group & $9 / 35$ & $1 / 7$ & 0.461 & $3 / 16$ & $6 / 16$ & 0.217 \\
\hline International staging system & & & 0.742 & & & 0.647 \\
\hline Stage I & $19(86)$ & $3(14)$ & & $6(43)$ & $8(57)$ & \\
\hline Stage II & $14(78)$ & $4(22)$ & & $6(43)$ & $8(57)$ & \\
\hline Stage III & $11(79)$ & $3(21)$ & & $6(60)$ & $4(40)$ & \\
\hline Durie-Salmon stage & & & 0.753 & & & 0.766 \\
\hline Stage I & $5(100)$ & $0(0)$ & & $2(67)$ & $1(33)$ & \\
\hline Stage II & $9(82)$ & $2(18)$ & & $3(38)$ & $5(62)$ & \\
\hline Stage III & $30(77)$ & $9(23)$ & & $13(48)$ & $14(52)$ & \\
\hline IMWG risk & & & 0.867 & & & 0.791 \\
\hline Low & $8(82)$ & $1(18)$ & & $3(60)$ & $2(40)$ & \\
\hline Standard & $30(79)$ & $8(21)$ & & $12(46)$ & $14(54)$ & \\
\hline High & $6(86)$ & $1(14)$ & & $3(43)$ & $4(47)$ & \\
\hline
\end{tabular}


TABLE 2: Continued.

\begin{tabular}{|c|c|c|c|c|c|c|}
\hline \multirow{2}{*}{ Clinical parameters } & \multicolumn{3}{|c|}{$\begin{array}{c}\text { CD33 } \\
\text { Mean or number (\%) }\end{array}$} & \multicolumn{3}{|c|}{$\begin{array}{c}\text { CD13 } \\
\text { Mean or number }(\%)\end{array}$} \\
\hline & $\begin{array}{l}\text { Negative } \\
(N=44)\end{array}$ & $\begin{array}{l}\text { Positive } \\
(N=10)\end{array}$ & $P$ & $\begin{array}{l}\text { Negative } \\
(N=18)\end{array}$ & $\begin{array}{c}\text { Positive } \\
(N=20)\end{array}$ & $P$ \\
\hline IMWG response & & & 0.742 & & & 0.698 \\
\hline Complete response & $8(80)$ & $2(20)$ & & $4(50)$ & $4(50)$ & \\
\hline Very good partial response & $6(86)$ & $1(14)$ & & $2(40)$ & $3(60)$ & \\
\hline Partial response & $10(83)$ & $2(17)$ & & $5(71)$ & $2(29)$ & \\
\hline Stable disease & $1(50)$ & $1(50)$ & & $1(100)$ & $0(0)$ & \\
\hline Progressive disease & $5(71)$ & $2(29)$ & & $3(43)$ & $4(57)$ & \\
\hline
\end{tabular}

BM: bone marrow; LDH: lactate dehydrogenase; IMWG: International Myeloma Working Group; ${ }^{\ddagger}$ numbers of positive cases among FISH tests done; percentages were not written because meanings were different from that of other parameters; ${ }^{{ }^{9}}$ including $\mathrm{t}(4 ; 14)$ or del(17p).

TABLE 3: Multivariate regression analysis of factors significantly associated with PFS and OS.

\begin{tabular}{|c|c|c|c|c|c|c|}
\hline \multirow{2}{*}{ Variables } & \multicolumn{3}{|c|}{ PFS } & \multicolumn{3}{|c|}{ OS } \\
\hline & $\mathrm{HR}$ & $95 \% \mathrm{CI}$ & $P$ & $\mathrm{HR}$ & $95 \% \mathrm{CI}$ & $P$ \\
\hline CD13+ & 3.46 & $0.8-14.8$ & 0.093 & 2.77 & $0.4-17.7$ & 0.283 \\
\hline CD33+ & 3.86 & $1.1-13.7$ & 0.037 & 13.8 & $3.1-61.3$ & 0.001 \\
\hline$\beta 2-$ Microglobulin $>3.5 \mathrm{mg} / \mathrm{dL}$ & 6.93 & $2.0-24.1$ & 0.002 & 4.02 & $1.0-16.7$ & 0.055 \\
\hline $\mathrm{LDH}>202 \mathrm{U} / \mathrm{L}$ & 1.84 & $0.5-6.9$ & 0.370 & 2.88 & $0.6-14.2$ & 0.195 \\
\hline Age $\geq 65$ years & 0.40 & $1.1-0.1$ & 0.076 & 1.50 & $0.5-4.6$ & 0.481 \\
\hline $\mathrm{t}(4 ; 14)$ & 0.51 & $0.1-2.2$ & 0.368 & 1.21 & $0.2-6.4$ & 0.823 \\
\hline
\end{tabular}

PFS: progression free survival; OS: overall survival; HR: hazard ratio; CI: confidence interval.

short OS; moreover multivariate analysis showed that CD33 expression was independent prognostic factor for poor prognosis. Both CD13+/CD33+ group showed significantly short OS and PFS and it suggests that expression of CD13 and CD33 has additive effect on unfavorable prognosis even though each group was not big enough to conclude. Though CD33 expression on plasma cells showed significant difference in OS, it did not show correlation with PFS. Since our study has limitation which included several treatment regimens, PFS which reflects more treatment response rather than biologic entity of myeloma did not reached the significant level.

With correlation of clinical parameters, the previous study has shown $\mathrm{CD} 33$ positivity was associated with higher serum $\mathrm{LDH}$ and $\beta 2$-microglobulin concentrations and higher incidence rates of anemia or thrombocytopenia [16], and this study showed a significant association between CD33 positivity and higher serum LDH concentration $(P=$ $0.018)$. For cytogenetic risk, there was the study showing higher incidence of $t(4 ; 14)$ in CD33-positive patients [17]; however, the association with $t(4 ; 14)$ was not observed in our study.

For mechanism of CD13 and CD33 in myeloma cells, there was no suggested pathway. The normal function of $\mathrm{CD} 13$ and $\mathrm{CD} 33$ in myeloid lineage is a zinc-dependent metalloproteinase anchored to cells as a type II transmembrane protein [18] and a sialic acid dependent cell adhesion molecule with a cytoplasmic tail bearing two tyrosine residues [19] which recruits Src homology-2 domaincontaining tyrosine phosphatases [20]. These markers have been shown correlation with cancer in increased motility of lung cancer cells resulting in high invasiveness [21] and drug resistance and refractoriness with significantly lower 1-year survival rate in MM [16].

The clue why our study represented correlation with prognosis lied in plasma cell type and infiltration pattern. Morphologic subtype of MM plasma cells and infiltration pattern were reported as prognostic factors by the previous studies, which showed plasmablastic cells and diffuse infiltrations were associated with poor prognosis [22-24]. In the present study, immature and plasmablastic types of plasma cells were significantly associated with CD33 positivity. This implicated CD33+ myeloma associated with poorly differentiated neoplastic plasma cell type. Also CD13+ myeloma patients showed either focal or diffuse pattern of infiltration which suggests the association of antigen expression with infiltration characteristics.

For other antigen expressions, we found that $56 \%$ of patients were positive for CD56, $53 \%$ for $\mathrm{CD} 13,18 \%$ for CD33, 9\% for CD117, and 6\% for CD20. In comparison, previous studies have found that $60-75 \%$ of MM patients were positive for $\mathrm{CD} 56,18-35 \%$ for CD $33,32 \%$ for CD117, and $17-30 \%$ for CD20 [9, 17, 25-27]. These discrepancies in the antigen expression frequencies could result from the differences in the definition of neoplastic plasma cell; some studies exclude CD138+, CD19+, CD45+, CD27+, CD56-, and CD20 - cells because they were regarded as normal plasma cells [8], but we included all CD138+ gated cells. The immunophenotypic definition of neoplastic plasma cells remains still unclear, because antigen expression profiles in normal or benign plasma cells are not uniform. Other 

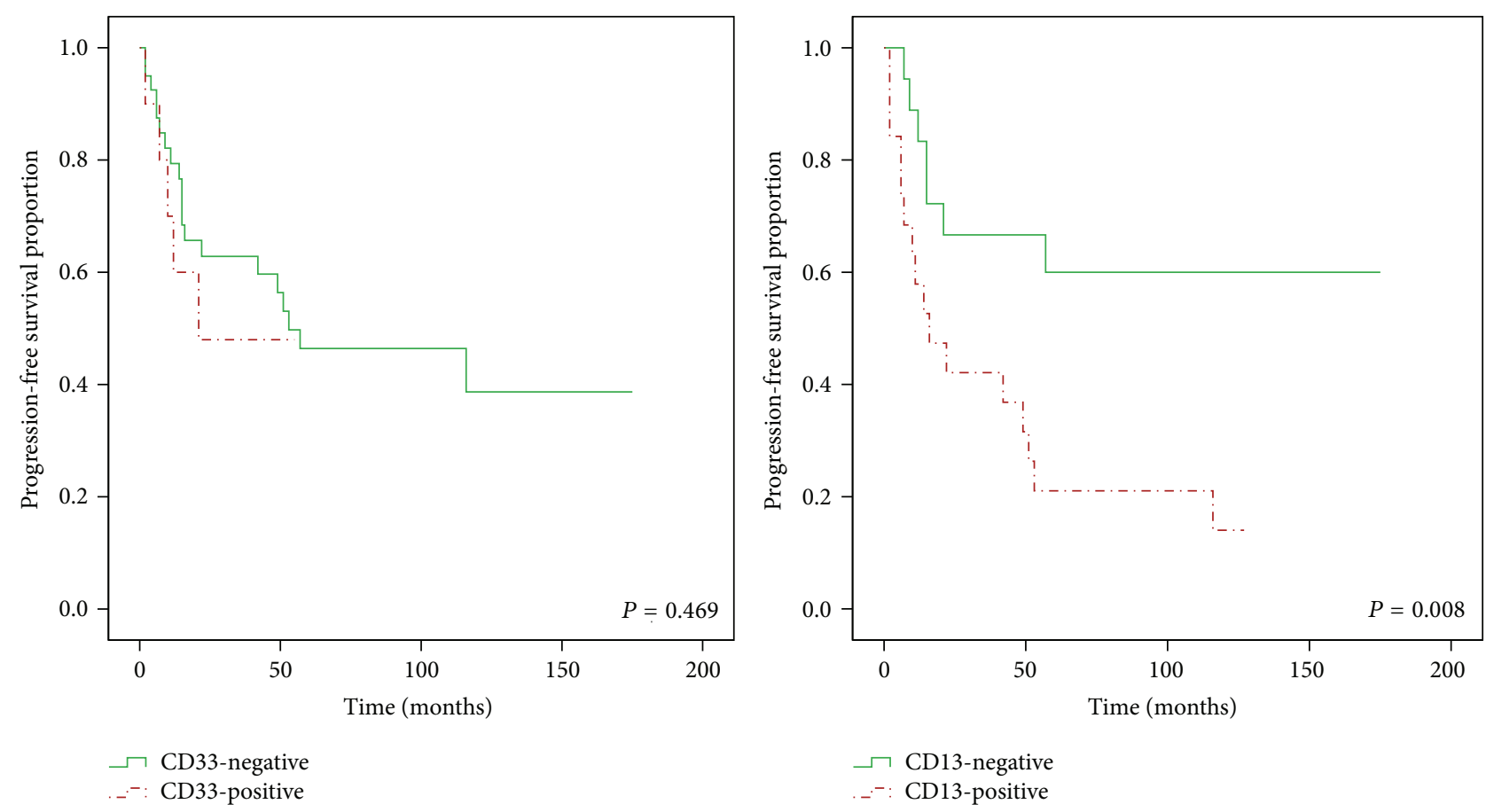

(a)
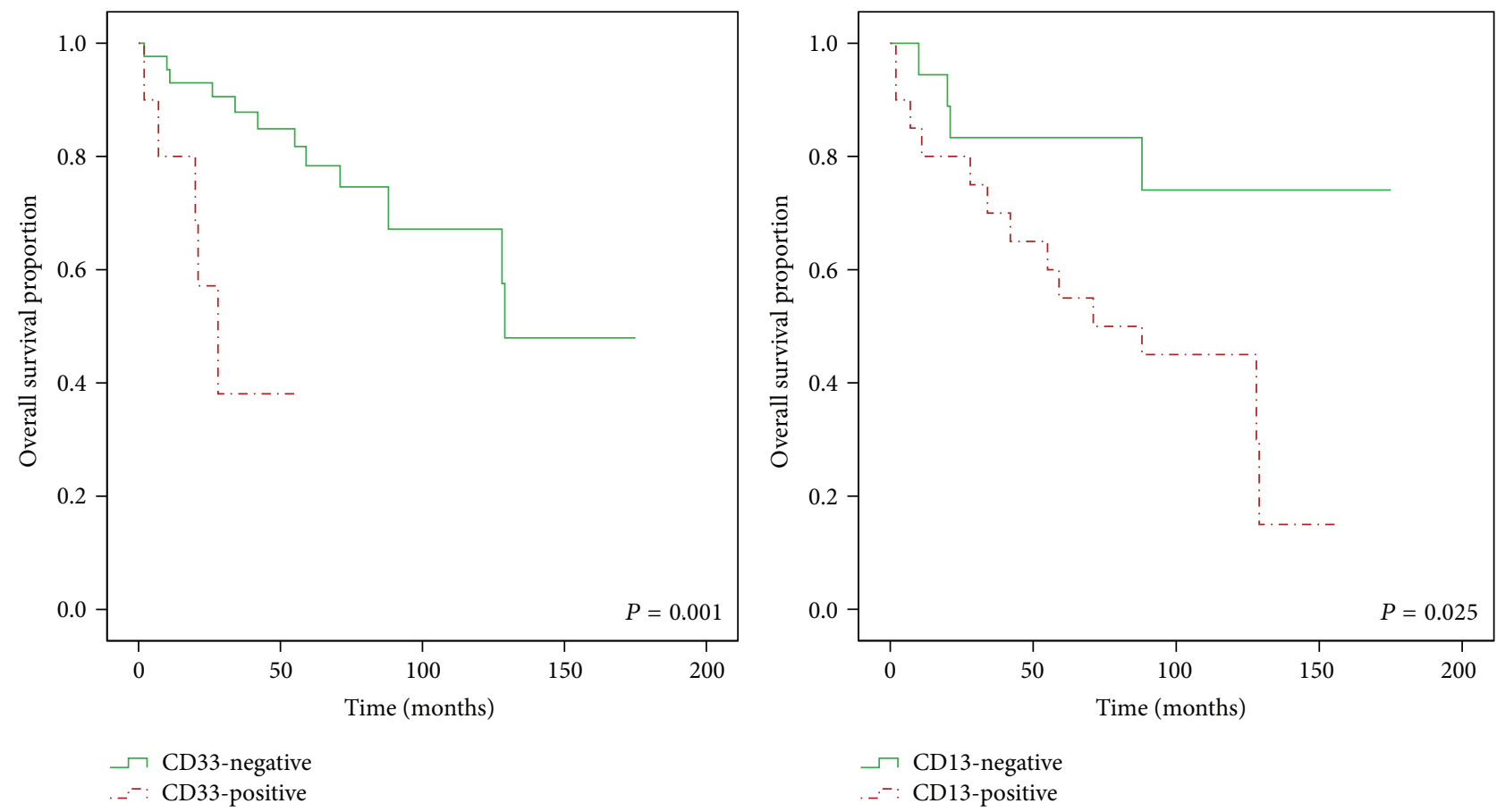

(b)

FIGURE 2: Kaplan-Meier analysis of (a) progression free survival (PFS) and (b) overall survival (OS) in groups of patients positive and negative for CD33 and CD13. CD33 expression demonstrates a potential prognostic impact and was associated with lower OS $(P=0.001)$. Patients with CD13 associated with significantly shorter PFS times $(P=0.008)$, not only lower OS $(P=0.025)$.

traditional myeloid markers have shown divergent impact in patients with MM. CD117, c-kit receptor, has been associated with good prognosis $[3,28]$ or not associated with prognosis [29-31]. The mechanism was explained as follows: CD117 expression might act as anchor molecule resulting in a decrease spread of plasma cells for good prognosis [28]. In this study, CD117+ patients did not display neither different disease characteristics nor a worse outcome. It might be due 


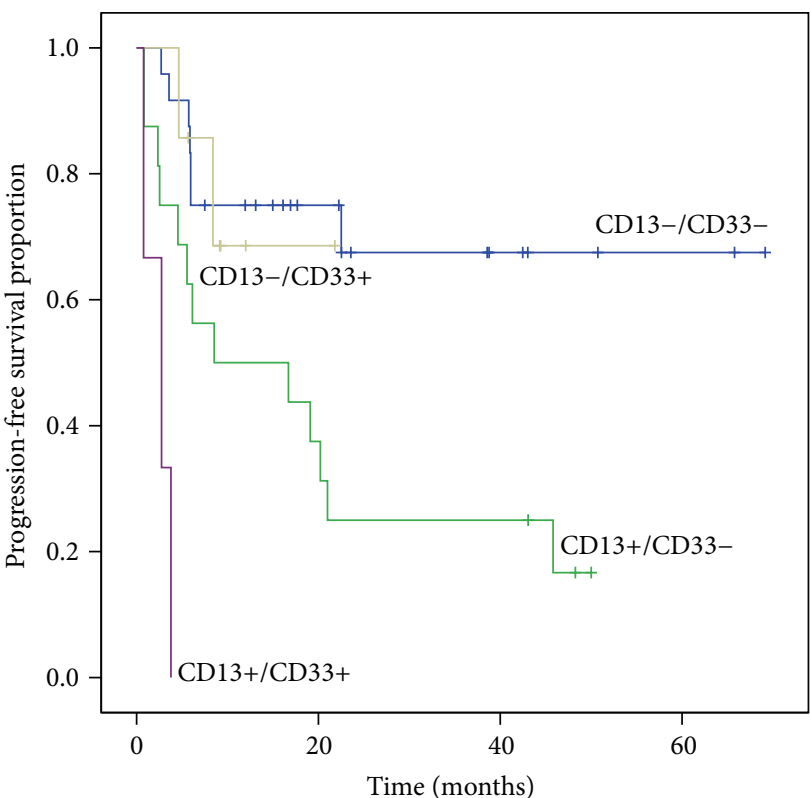

(a)

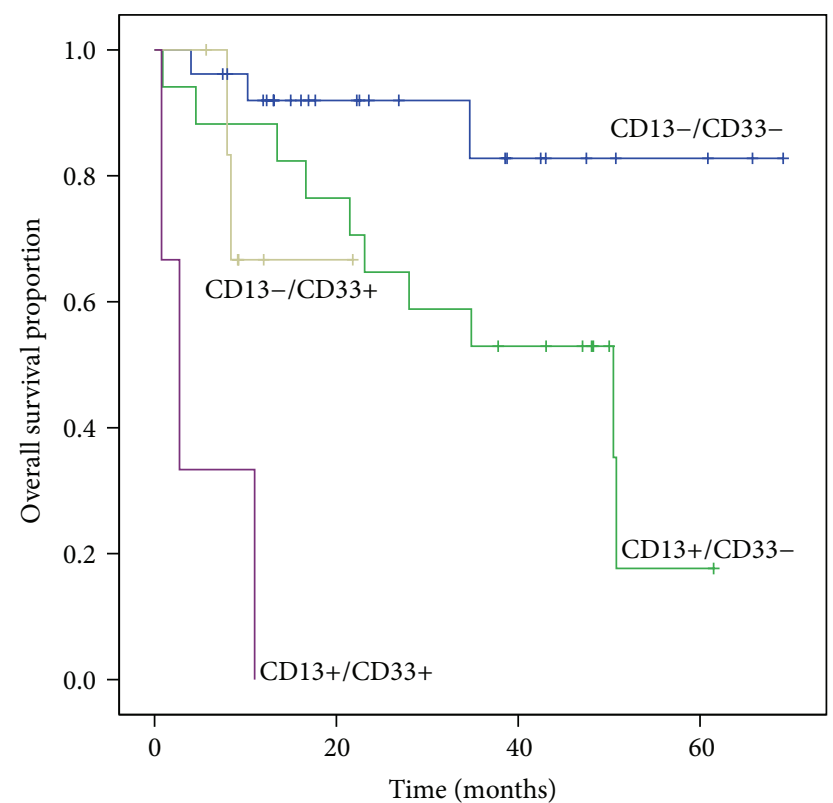

(b)

Figure 3: Kaplan-Meier analysis of (a) PFS and (b) OS in groups of patients with CD13-/CD33-, CD13-/CD33+, CD13+/CD33-, and $\mathrm{CD} 13+/ \mathrm{CD} 33+$. The CD13+/CD33+ group showed significantly shorter PFS and OS than other groups: CD13-/CD33- group $(P<0.001$ in PFS and OS), CD13+/CD33- group $(P=0.013$ in PFS and $P<0.001$ in OS), and CD13-/CD33+ group $(P=0.001$ in PFS, $P=0.049$ in OS). CD13+/CD33- group showed significantly shorter PFS and OS than CD13-/CD33- group $(P=0.006$ in PFS, $P=0.020$ in OS).

to low frequency of CD117 positivity in the present study, which could result from different destination of neoplastic plasma cells.

The major limitation of this study was the lack of homogenous treatment. However, CD33 expression was associated with significant short OS in both patients who underwent PBSCT $(n=16, P<0.001)$ or who did not $(P=0.046)$. Thus, our findings implicate the need of analysis of these markers in MM diagnosis.

\section{Conclusion}

In conclusion, this study showed that the expression of CD13 and CD33 in neoplastic plasma cells from patients with MM was associated with poor prognosis independently of other prognostic factors. Further study is needed to clarify the role of these markers in MM pathogenesis.

\section{Conflict of Interests}

All authors declare that there is no conflict of interests regarding the publication of this paper.

\section{Authors' Contribution}

Hyoeun Shim and Joo Hee Ha equally contributed to this work.

\section{References}

[1] F. E. Craig and K. A. Foon, "Flow cytometric immunophenotyping for hematologic neoplasms," Blood, vol. 111, no. 8, pp. 39413967, 2008.

[2] B. Paiva, J. Almeida, M. Perez-Andres et al., "Utility of flow cytometry immunophenotyping in multiple myeloma and other clonal plasma cell-related disorders," Cytometry B: Clinical Cytometry, vol. 78, no. 4, pp. 239-252, 2010.

[3] R. Bataille, G. Jego, N. Robillard et al., "The phenotype of normal, reactive and malignant plasma cells. Identification of "many and multiple myelomas" and of new targets for myeloma therapy," Haematologica, vol. 91, no. 9, pp. 1234-1240, 2006.

[4] W. Eisterer, O. Bechter, W. Hilbe et al., "CD44 isoforms are differentially regulated in plasma cell dyscrasias and CD44v9 represents a new independent prognostic parameter in multiple myeloma," Leukemia Research, vol. 25, no. 12, pp. 1051-1057, 2001.

[5] C. Pellat-Deceunynck, S. Barille, G. Jego et al., "The absence of CD56 (NCAM) on malignant plasma cells is a hallmark of plasma cell leukemia and of a special subset of multiple myeloma," Leukemia, vol. 12, no. 12, pp. 1977-1982, 1998.

[6] N. Robillard, C. Pellat-Deceunynck, and R. Bataille, "Phenotypic characterization of the human myeloma cell growth fraction," Blood, vol. 105, no. 12, pp. 4845-4848, 2005.

[7] N. J. Bahlis, A. M. King, D. Kolonias et al., "CD28-mediated regulation of multiple myeloma cell proliferation and survival," Blood, vol. 109, no. 11, pp. 5002-5010, 2007.

[8] Y. U. Cho, C. J. Park, S. J. Park et al., "Immunophenotypic characterization and quantification of neoplastic bone marrow plasma cells by multiparametric flow cytometry and its clinical 
significance in Korean myeloma patients," Journal of Korean Medical Science, vol. 28, no. 4, pp. 542-549, 2013.

[9] G. Mateo, M. A. Montalban, M.-B. Vidriales et al., "Prognostic value of immunophenotyping in multiple myeloma: a study by the PETHEMA/GEM cooperative study groups on patients uniformly treated with high-dose therapy," Journal of Clinical Oncology, vol. 26, no. 16, pp. 2737-2744, 2008.

[10] H. E. Johnsen, M. Bogsted, T. W. Klausen et al., "Multiparametric flow cytometry profiling of neoplastic plasma cells in multiple myeloma," Cytometry B: Clinical Cytometry, vol. 78, no. 5, pp. 338-347, 2010.

[11] R. A. Kyle and S. V. Rajkumar, "Criteria for diagnosis, staging, risk stratification and response assessment of multiple myeloma," Leukemia, vol. 23, no. 1, pp. 3-9, 2009.

[12] B. G. Durie and S. E. Salmon, "A clinical staging system for multiple myeloma. Correlation of measured myeloma cell mass with presenting clinical features, response to treatment, and survival," Cancer, vol. 36, no. 3, pp. 842-854, 1975.

[13] P. R. Greipp, J. S. Miguel, B. G. Dune et al., "International staging system for multiple myeloma," Journal of Clinical Oncology, vol. 23, no. 15, pp. 3412-3420, 2005.

[14] B. G. Durie, J.-L. Harousseau, J. S. Miguel et al., "International uniform response criteria for multiple myeloma," Leukemia, vol. 20, no. 9, pp. 1467-1473, 2006.

[15] W. J. Chng, A. Dispenzieri, C. S. Chim et al., "IMWG consensus on risk stratification in multiple myeloma," Leukemia, vol. 28, no. 2, pp. 269-277, 2014.

[16] N. Sahara, K. Ohnishi, T. Ono et al., "Clinicopathological and prognostic characteristics of CD33-positive multiple myeloma," European Journal of Haematology, vol. 77, no. 1, pp. 14-18, 2006.

[17] N. Robillard, S. Wuilleme, L. Lode, F. Magrangeas, S. Minvielle, and H. Avet-Loiseau, "CD33 is expressed on plasma cells of a significant number of myeloma patients, and may represent a therapeutic target," Leukemia, vol. 19, no. 11, pp. 2021-2022, 2005.

[18] D. Riemann, A. Kehlen, and J. Langner, "CD13-not just a marker in leukemia typing," Immunology Today, vol. 20, no. 2, pp. 83-88, 1999.

[19] S. D. Freeman, S. Kelm, E. K. Barber, and P. R. Crocker, "Characterization of CD33 as a new member of the sialoadhesin family of cellular interaction molecules," Blood, vol. 85, no. 8, pp. 2005-2012, 1995.

[20] S. P. Paul, L. S. Taylor, E. K. Stansbury, and D. W. McVicar, "Myeloid specific human CD33 is an inhibitory receptor with differential ITIM function in recruiting the phosphatases SHP1 and SHP-2," Blood, vol. 96, no. 2, pp. 483-490, 2000.

[21] Y.-W. Chang, S.-C. Chen, E.-C. Cheng et al., "CD13 (aminopeptidase N) can associate with tumor-associated antigen L6 and enhance the motility of human lung cancer cells," International Journal of Cancer, vol. 116, no. 2, pp. 243-252, 2005.

[22] P. R. Greipp, N. M. Raymond, R. A. Kyle, and W. M. O’Fallon, "Multiple myeloma: significance of plasmablastic subtype in morphological classification," Blood, vol. 65, no. 2, pp. 305-310, 1985.

[23] A. Carter, I. Hocherman, S. Linn, Y. Cohen, and I. Tatarsky, "Prognostic significance of plasma cell morphology in multiple myeloma," Cancer, vol. 60, no. 5, pp. 1060-1065, 1987.

[24] R. Subramanian, D. Basu, and T. K. Dutta, "Prognostic significance of bone marrow histology in multiple myeloma," Indian Journal of Cancer, vol. 46, no. 1, pp. 40-45, 2009.
[25] J. Drach, C. Gattringer, and H. Huber, "Expression of the neural cell adhesion molecule (CD56) by human myeloma cells," Clinical and Experimental Immunology, vol. 83, no. 3, pp. 418-422, 1991.

[26] N. Robillard, H. Avet-Loiseau, R. Garand et al., "CD20 is associated with a small mature plasma cell morphology and t(11;14) in multiple myeloma," Blood, vol. 102, no. 3, pp. 10701071, 2003.

[27] A. M. Harrington, P. Hari, and S. H. Kroft, "Utility of CD56 immunohistochemical studies in follow-up of plasma cell myeloma," American Journal of Clinical Pathology, vol. 132, no. 1, pp. 60-66, 2009.

[28] M. Schmidt-Hieber, M. Perez-Andres, B. Paiva et al., "CD117 expression in gammopathies is associated with an altered maturation of the myeloid and lymphoid hematopoietic cell compartments and favorable disease features," Haematologica, vol. 96, no. 2, pp. 328-332, 2011.

[29] M. Ocqueteau, A. Orfao, R. Garcia-Sanz, J. Almeida, M. Gonzalez, and J. F. S. Miguel, "Expression of the CD117 antigen (CKit) on normal and myelomatous plasma cells," British Journal of Haematology, vol. 95, no. 3, pp. 489-493, 1996.

[30] M. Kraj, R. Poglod, J. Kopec-Szlezak, U. Sokolowska, J. Wozniak, and B. Kruk, "C-kit receptor (CD117) expression on plasma cells in monoclonal gammopathies," Leukemia and Lymphoma, vol. 45, no. 11, pp. 2281-2289, 2004.

[31] G. Pruneri, M. Ponzoni, A. J. M. Ferreri et al., “The prevalence and clinical implications of c-kit expression in plasma cell myeloma," Histopathology, vol. 48, no. 5, pp. 529-535, 2006. 


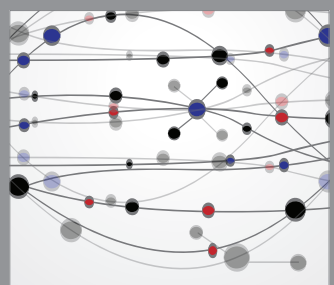

The Scientific World Journal
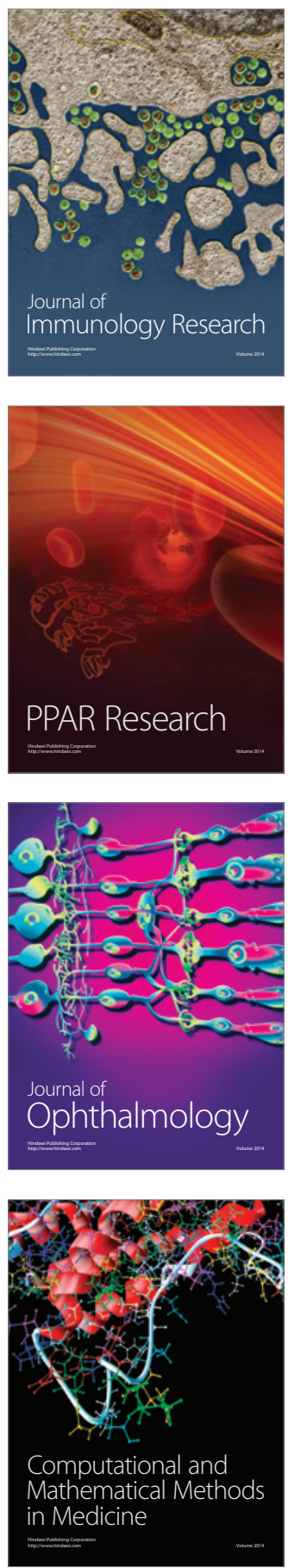

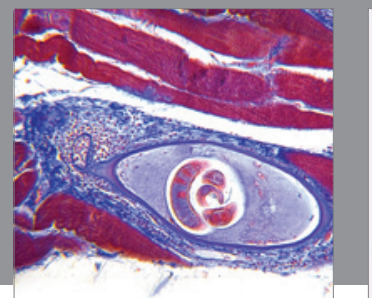

Gastroenterology

Research and Practice
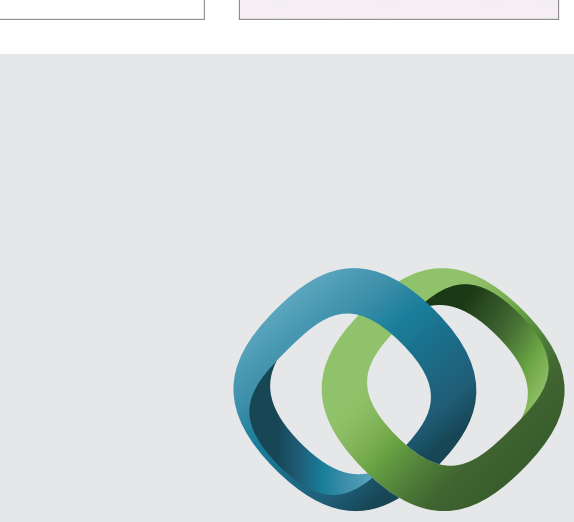

\section{Hindawi}

Submit your manuscripts at

http://www.hindawi.com
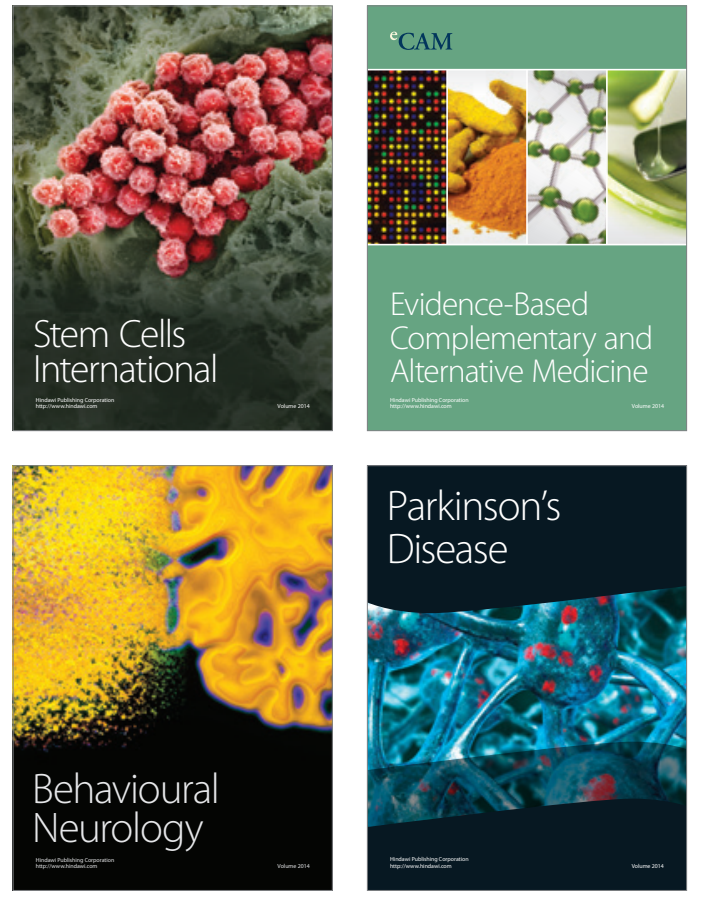
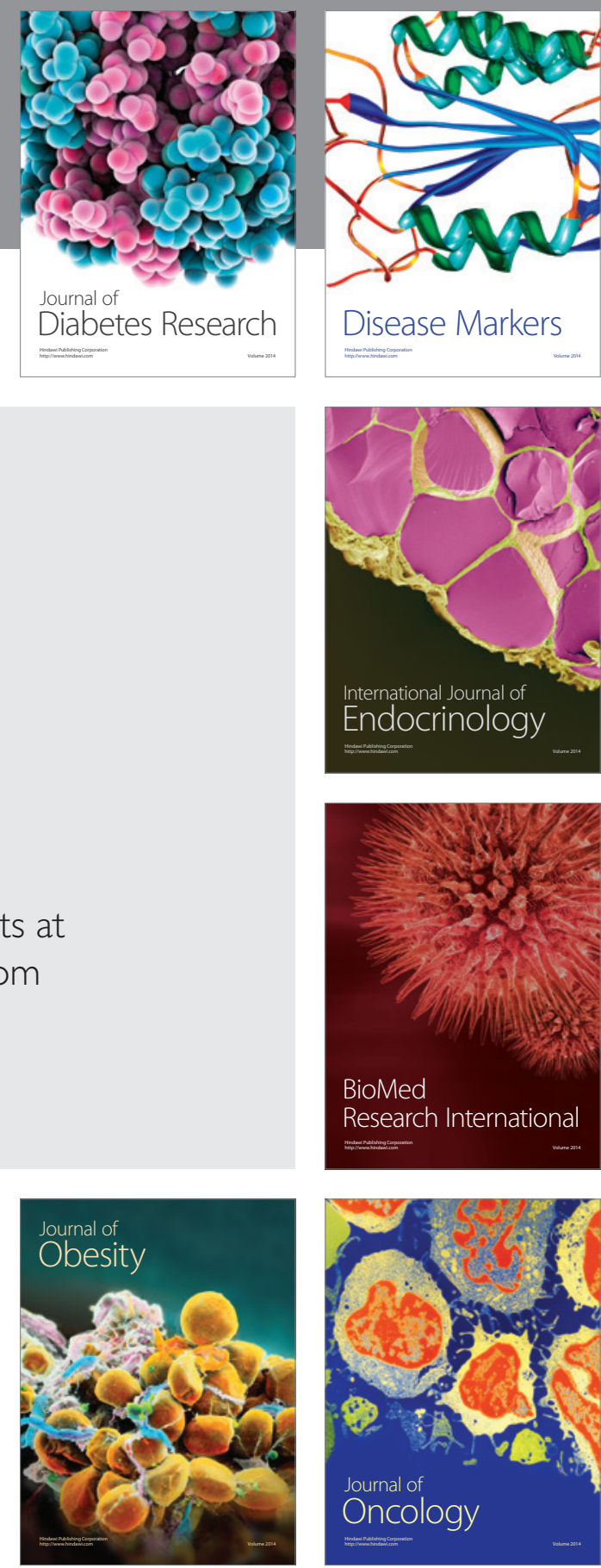

Disease Markers
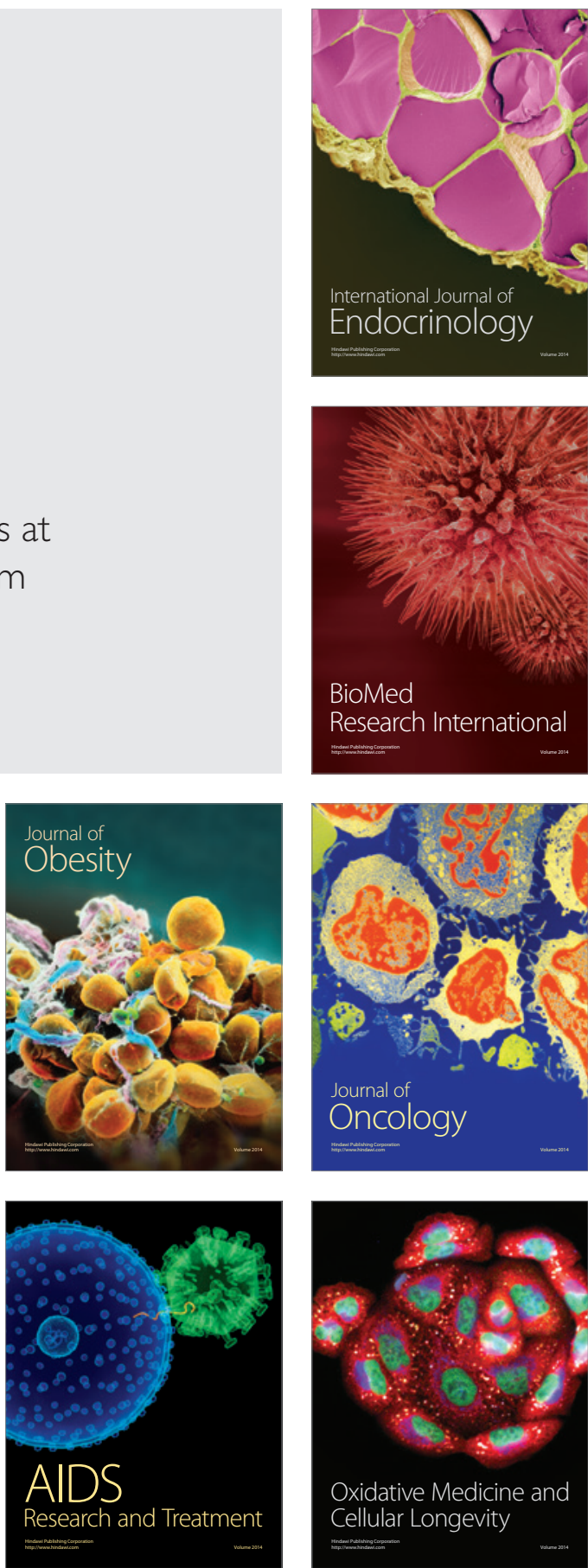